of large characters formed by a grid of adjacent character cells, each of which displays a segment of an enlarged character. A public-domain program (Mefford, 1988) can be used to create and modify VGA font files. This program produces executable files that load a customized font into the VGA controller, where it becomes available to any program (including the tachistoscope functions) that displays text on the screen.

VGA controllers are well suited to tachistoscope emulation. All of the necessary functions (virtual screen storage, display blanking, cursor control, and video synchronization) are included in the VGA's Basic Input/Output Software (BIOS), which is stored in a read-only memory on the VGA circuit board. In the Hercules, CGA, and EGA controllers, a complete set of tachistoscope functions cannot be created without programming the display controller's registers directly. Programs that use this approach may not work equally well on all display controllers, because of internal hardware differences. This problem should not arise with the VGA tachistoscope functions, since they access the VGA controller through its BIOS software.

\section{Availability}

A printed listing of the VGA tachistoscope functions and a demonstration program will be sent on request. To obtain a copy of the files on disk (5.25 or 3.5 in.), send a blank, formatted disk to the author. Please specify the $C$ or Pascal version of the package. In addition, a description of how the functions could be recoded into subroutines in BASIC will be included. The author may be contacted on e-mail at USERGFSO@MTS.UCS.UALBERTA.CA.

\section{REFERENCES}

FinLEy, G. P. (1989). Tachistoscopic software for the Hercules display controller. Behavior Research Methods, Instruments, \& Computers, 21, 387-390.

Gerrold, D. (1990). Free your VGA from CGA captivity with Prism.exe. PC Magazine, 9 (21), 463-480.

Mefrord, M. J. (1988). Making your own screen fonts. PC Magazine, 7 (15), 305-324.

(Manuscript received February 15, 1991; revision accepted for publication June 3,1991 .)

\title{
Call for Assistance in The Compilation of a History of the Psychonomic Society
}

The Governing Board of the Psychonomic Society is pleased to announce that Robert C. Bolles has agreed to serve as the first Historian of the Society.

All members who might have information relevant to this undertaking are invited to send it directly to Dr. Bolles. Founding members and those who attended the early meetings are especially encouraged to record their reminiscences. While Dr. Bolles hopes to collect as much information as possible relevant to the history of the Society, he will concentrate first on the early history.

Dr. Bolles's address is Department of Psychology, University of Washington, Seattle, Washington 98195 (phone: 206-543-2631). 